\title{
Does Adult Intestinal Invagination Need Surgery? Report of a Case and Review of Literature
}

\author{
Carlos Leon-Espinoza ${ }^{1}$, Maria Gomez-Mateo ${ }^{2}$, Fernando Lopez-Mozos ${ }^{1}$, Roberto Marti-Obiol ${ }^{1}$, \\ Juan Raga-Vazquez ${ }^{1}$, Joaquin Ortega-Serrano ${ }^{1}$
}

${ }^{1}$ Department of General y Digestive Surgery, Valencia, Spain; ${ }^{2}$ Department of Pathology, Hospital Clínico Universitario Valencia,
Valencia, Spain.

Email: caleon17@hotmail.com

Received January $25^{\text {th }}, 2011$; revised February $12^{\text {th }}, 2011$; accepted May $5^{\text {th }}, 2011$.

\begin{abstract}
Benign intestinal tumors are the most frequent cause of small bowel intussusception in adults. This report presents a case of a 67-year-old male with abdominal pain, leukocytosis and C-reactive protein elevation. After ultrasonography and double contrast CT-scan consistent with ileal intussusception patient underwent laparoscopy, which confirmed diagnose. Intestinal resection and anastomosis were performed via minilaparotomy. Further histological study showed a fibroid inflammatory polyp or Vanek's tumor as intussusception's lead point.
\end{abstract}

Keywords: Invagination, Intussusception, Vanek

\section{Introduction}

Intestinal invagination is an uncommon condition in adults. It represents about $5 \%$ of the invaginations, which are most frequently presented in children [1].

Intestinal obstruction is its most common presentation in adults and is usually diagnosed intraoperatively. Other symptoms that could be observed are gastrointestinal bleeding or chronic abdominal pain.

The most common cause of intussusception is the presence of an intestinal tumor, usually benign in the small bowel while malignant in colon.

We present a case report of an adult intestinal invagination caused by a Vanek's tumor.

\section{Case Report}

A 67-year-old hypertensive male was admitted on ER because of a 24-hour abdominal pain localized on the right lower quadrant. Physical examination showed a non-distended abdomen, normal bowel sounds and right lower quadrant tenderness. No peritoneal signs were found.

Laboratory investigation revealed: 13,800 leukocytes/ $\mu 1$ ( $80.7 \%$ segmented neutrophils, $12.4 \%$ lymphocytes), hemoglobin value of $14.7 \mathrm{~g} / \mathrm{dl}$ and a C-reactive protein of $98.0 \mathrm{mg} / \mathrm{L}$. Abdominal X-ray showed normal gas pattern. An abdominal ultrasonography was performed revealing an image compatible with intestinal intussusception lo- calized at the right lower quadrant. Enhanced contrast CT-scan was performed for further evaluation, showing an ileo-ileal invagination without identifying a lead point.

As patient improved clinically and stayed asymptomatic, emergency surgery was not considered and the patient was admitted in the surgery ward. Two days later a double contrast CT-scan was performed identifying a persistent "doughnut" sign that was highly suspicious of intussusception.

Due to the findings on the CT-scan, a diagnostic laparoscopy was performed, identifying a non-reducible ileo-ileal invagination without macroscopic signs of intestinal ischaemia. A $25 \mathrm{~cm}$ intestinal resection through minilaparotomy was carried out followed by a side-toside hand-sewn anastomosis. Patient made an uneventful postoperative recovery and was discharged four days later.

Histologic study showed a polypoid lesion as the intussusception's lead point, originated on the subserosa formed by fibroblastic cells. It also showed an inflammatory infiltrate of eosinophyls and mastocytes and the diagnosis of Fibroid Inflammatory Polyp or Vanek's Tumor was then established (Figure 1).

\section{Discussion}

Intestinal intussusception is a rare condition in adults (5\% $-10 \%$ of all intussusceptions [1,2]), usually caused 


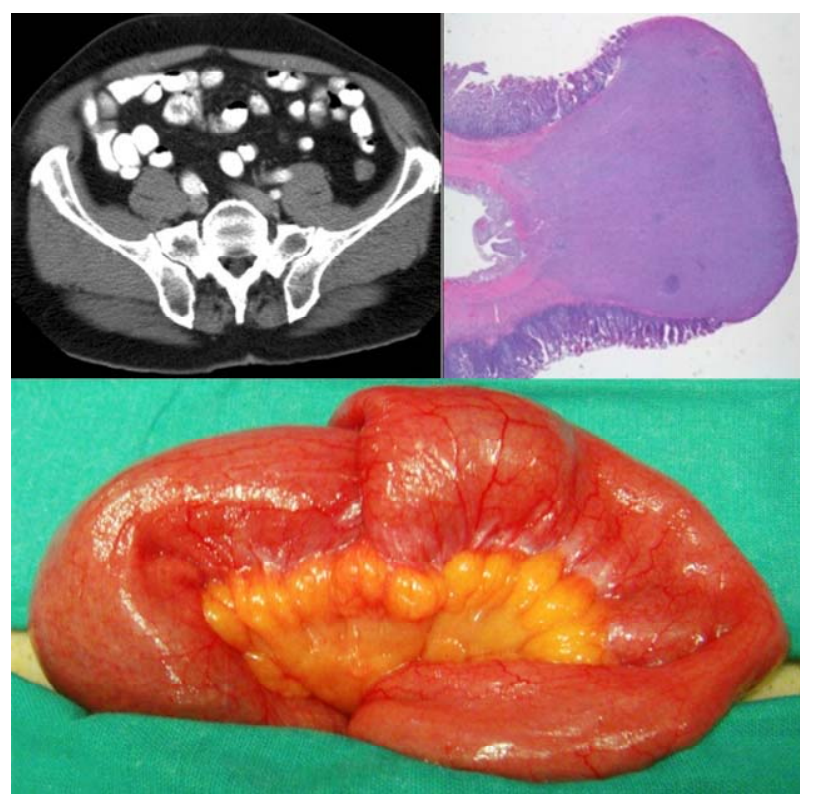

Figure 1. Radiologic, anatomic and pathological intussusception's correspondence.

by tumors. These can be benign, malignant or inflammatory. In the small bowel benign conditions such as Meckel's diverticulum, adhesions or benign tumors are most frequently presented but also malignant processes can be found such as metastatic implants. Malignant processes, usually adenocarcinomas, are most common in the large intestine. Foreign bodies have been rarely described as a cause of invagination.

Inflammatory Polyps are rare benign lesions of the gastrointestinal tract. They arise from the submucosa and grow as polypoid masses. Vanek initially described this type of lesion in 1949 as a gastric granuloma with eosinophilic infiltration [3].

This tumor has a higher incidence on the sixth and seventh decade of life just as it happened on our patient. Vanek's tumors are most often observed in the gastric antrum and ileum, and are sometimes microscopically mistaken with a variety of lesions, from granulation tissue to high-grade sarcoma. In the differential diagnosis, it is important to include eosinophilic gastroenteritis, gastrointestinal stromal tumor, inflammatory pseudo tumor, haemangioendothelioma and haemangiopericytom [4].

Gastrointestinal bleeding, total or partial intestinal occlusion and intestinal invagination are the most frequent symptoms. Fever, polyarthritis, polyarthralgia, elevated erythrocyte sedimentation rate, leukocytosis or thrombocytosis are some uncommon reported findings ${ }^{4}$. Ultrasonography, CT-scan, endoscopy and double-balloon endoscopy are some of the studies which could be helpful for the diagnosis [5]. Inflammatory Polyp's resection are considered curative and no follow-up is then re- quired.

Most of the reports published are related to single acute cases due to the rare incidence of this condition[5].

Diagnosis can be delayed because of its longstanding, intermittent, and non-specific symptoms, and most cases are diagnosed at laparotomy [6].

In our case, images from ultrasonography and CT-scan showed us the certain diagnosis. As our patient didn't show any symptoms after admission, we decide to perform a differed exploratory laparoscopy, which led as to the definitive diagnosis.

Management of intussusception in adults differs from that in children. Some authors even consider them as two different entities due to their mayor differences in the clinical presentation, diagnostic approach, and management $[2,7]$. Nevertheless, surgical treatment is also recommended in children when a suspected pathological lead point is present [8]. Several different treatments were initially proposed for adults, but most latest's reviews recommend surgery as treatment $[2,9]$ and consider hydrostatic reduction as "not mandatory" [10].

Management of intestinal intussusception in adults should consider the resection of the intestine affected [11], as well as reduction and resection, when no malignant pathology is suspected and a long portion of viable intestine is affected [2,12]. Nevertheless reduction is still controversial because of the high incidence on intussusceptions' malignant origin [6].

On non-operated adults with occlusive or GI hemorrhagic episodes, once colonic and gastric causes have been excluded, we must consider intestinal invagination as differential diagnosis. Despite of its low incidence most times a definitive surgical approach is required.

\section{REFERENCES}

[1] T. Azar and D. L. Berger, "Adult Intussusception," Annals of Surgery, Vol. 226, No. 2, 1997, pp. 134-138. doi:10.1097/00000658-199708000-00003

[2] A. Demirkan, A. Yağmurlu, I. Kepenekci, et al., "Intussusception in Adult and Pediatric Patients: Two Different Entities," Surgery Today, Vol. 39, No. 10, 2009, pp. 861865. doi:10.1007/s00595-009-3979-8

[3] J. Vanek, "Gastric Submucosalgranuloma with Eosinophilic Infiltration," The American Journal of Pathology, Vol. 25, No. 3, 1949, pp. 397-411.

[4] D. Acero, G. Garijo, M. Hombrados, et al., "Gastrointestinal Inflammatory Fibroid Polyps. Clinical Characteristics and Follow-up in a Series of 26 Patients," Journal of Gastroenterology and Hepatology, Vol. 28, No. 4, 2005, pp. 215-220. doi:10.1157/13073089

[5] T. Miyata, H. Yamamoto, H. Kita, et al., "A Case of Inflammatory Fibroid Polyp Causing Small-Bowel Intussusception in Which Retrograde Double-Balloon En- 
teroscopy was Useful for the Preoperative Diagnosis," Endoscopy, Vol. 36, No. 4, 2004, pp. 344-347. doi:10.1055/s-2004-814305

[6] S. Yalamarthi and R. C. Smith, "Adult Intussusception: Case Reports and Review of Literature," Postgraduate Medical Journal, Vol. 81, No. 953, 2005, pp. 174-177. doi:10.1136/pgmj.2004.022749

[7] R. K. Gupta, C. S. Agrawal, R. Yadav, et al., "Intussusception in Adults: Institutional Review," International Journal of Surgery, Vol. 9, No. 1, 2011, pp. 91-95. doi:10.1016/j.ijsu.2010.10.003

[8] R. Niramis, S. Watanatittan, A. Kruatrachue, et al., "Management of Recurrent Intussusception: Nonoperative or Operative Reduction?" Journal of Pediatric Surgery, Vol. 45, No. 11, 2010, pp. 2175-2780.

[9] M. Barussaud, N. Regenet, X. Briennon, et al., "Clinical
Spectrum and Surgical Approach of Adult Intussusceptions: A Multicentric Study," International Journal of Colorectal Disease, Vol. 21, No. 8, 2006, pp. 834-839. doi:10.1007/s00384-005-0789-3

[10] H. Liu, Y. J., Cheng H. P. Chen, et al., "Multiple Bowel Intussusceptions from Metastatic Localized Malignant Pleural Mesothelioma: A Case Report," World Journal of Gastroenterology, Vol. 16, No. 31, 2010, pp. 3984-3946. doi:10.3748/wig.v16.i31.3984

[11] A. Landalucea, B. Estraviza, I. Barredob, et al., "Invaginación Intestinal en el Adulto: Diagnóstico y Actitud. Cirugía," Casos Clínicos, Vol. 3, No. 1, 2008, pp. 18-20.

[12] Zia Ur Rehman, A. R. Alvi and S. Khan, "Intussusceptions in Adults: Clinical Features and Operative Procedures," Journal of the College of Physicians and SurgeonsPakistan, Vol. 20, No. 12, 2010, pp. 790-793. 